\title{
Dynamics of C-reactive protein and white blood cell count in critically ill patients with nosocomial Gram positive vs. Gram negative bacteremia: a historical cohort study
}

\author{
Dominique M Vandijck ${ }^{* 1,3}$, Eric A Hoste ${ }^{1,3}$, Stijn I Blot ${ }^{1,3}$, Pieter O Depuydt ${ }^{1}$, \\ Renaat A Peleman ${ }^{2}$ and Johan M Decruyenaere ${ }^{1}$
}

Address: ${ }^{1}$ Department of Intensive Care Medicine, Ghent University Hospital - Ghent University, Faculty of Medicine and Health Sciences, De Pintelaan 185, Ghent, Belgium, ${ }^{2}$ Department of Infectious Diseases, Ghent University Hospital - Ghent University, Faculty of Medicine and Health Sciences, De Pintelaan 185, Ghent, Belgium and '3niversity College Ghent, Department of Health Care "Vesalius", Keramiekstraat 80, Ghent, Belgium

Email: Dominique M Vandijck* - Dominique.Vandijck@UGent.be; Eric A Hoste - Eric.Hoste@UGent.be; Stijn I Blot - Stijn.Blot@UGent.be; Pieter O Depuydt - Pieter.Depuydt@UGent.be; Renaat A Peleman - Renaat.Peleman@UGent.be; Johan M Decruyenaere - Johan.Decruyenaere@UGent.be

* Corresponding author

Published: 14 September 2007

BMC Infectious Diseases 2007, 7:106 doi:10.1186/147/-2334-7-106
Received: 23 October 2006

Accepted: 14 September 2007

This article is available from: http://www.biomedcentral.com/147I-2334/7/106

(c) 2007 Vandijck et al; licensee BioMed Central Ltd.

This is an Open Access article distributed under the terms of the Creative Commons Attribution License (http://creativecommons.org/licenses/by/2.0), which permits unrestricted use, distribution, and reproduction in any medium, provided the original work is properly cited.

\begin{abstract}
Background: Nosocomial bacteremia is associated with a poor prognosis. Early adequate therapy has been shown to improve outcome. Consequently, rapid detection of a beginning sepsis is therefore of the utmost importance. This historical cohort study was designed to evaluate if different patterns can be observed in either C-reactive protein (CRP) and white blood cell count (WCC) between Gram positive bacteremia (GPB) vs. Gram negative bacteremia (GNB), and to assess the potential benefit of serial measurements of both biomarkers in terms of early antimicrobial therapy initiation.
\end{abstract}

Methods: A historical study (2003-2004) was conducted, including all adult intensive care unit patients with a nosocomial bacteremia. CRP and WCC count measurements were recorded daily from two days prior $\left(d_{-2}\right)$ until one day after onset of bacteremia $\left(d_{+1}\right)$. Delta $(\Delta)$ CRP and $\Delta$ WCC levels from the level at $d_{-2}$ onward were calculated.

Results: CRP levels and WCC counts were substantially higher in patients with GNB. Logistic regression analysis demonstrated that GNB and Acute Physiology and Chronic Health Evaluation (APACHE) II score were independently associated with a CRP increase of $5 \mathrm{mg} / \mathrm{dL}$ from $d_{-2}$ to $d_{+1}$, and both were also independently associated with an increase of WCC levels from $d_{-2}$ to $d_{+1}$ of $5,000 \times 10^{3}$ cells $/ \mathrm{mm}^{3}$.

Conclusion: Increased levels of CRP and WCC are suggestive for GNB, while almost unchanged CRP and WCC levels are observed in patients with GPB. However, despite the different patterns observed, antimicrobial treatment as such cannot be guided based on both biomarkers. 


\section{Background}

Nosocomial bloodstream infection (BSI) is a major complication of intensive care unit (ICU) admission [1]. Physiological features such as fever, tachycardia and tachypnea have been proposed as indicators of sepsis $[2,3]$. These findings may be sensitive, but are less specific in the diagnosis of systemic inflammation or infection $[4,5]$. In this setting, C-reactive protein (CRP) and white blood cell counts (WCC) have been shown to be more reliable markers [6-8]. Early initiation of appropriate antimicrobials is a key to improve patients' survival [9]. Identification of the isolated pathogen including antibiogram is available at least 24-hrs after samples for blood cultures were performed. Early recognition of even the first minor signs of infection in case of a beginning bacteremia could therefore help to identify those patients who are more likely infected with either Gram positive or Gram negative pathogens [3]. The primary aim of our study was to investigate whether or not critically ill patients with nosocomial bacteremia caused by either Gram positive or Gram negative bacteria, present different patterns in the evolution of both biomarkers in order to facilitate decisions concerning the initial choice of an empiric antibiotic regimen.

\section{Methods \\ Setting}

The study was conducted in the Ghent University Hospital, a 1062-bed tertiary teaching care centre in Belgium. About 4100 patients are admitted to the 54-beds ICU annually.

\section{Study design}

A historical observational cohort study of prospectively collected data (2003-2004) was performed in which all episodes of microbiological documented nosocomial bacteremia occurring in adult ICU patients $(n=174)$ were included. All data (i.e. demographic, clinical, laboratory, and physiological) were gathered by reviewing the charts and the computerized hospital laboratory and administrative databases.

Serial measurements of CRP and WCC serum concentrations were gathered, starting two days prior to onset of bacteremia $\left(\mathrm{d}_{-2}\right)$ onwards until one calendar day (which is 48-hrs) after onset of bacteremia $\left(\mathrm{d}_{+1}\right)$ to record the respective patterns of both biomarkers. To evaluate the evolution over time, delta $(\Delta)$ CRP levels and $\Delta$ WCC levels were calculated relative to the level at $\mathrm{d}_{-2}$. Patient characteristics, laboratory variables, and antimicrobial therapies were compared between episodes of Gram positive and Gram negative bacteremia. For analysis, only the first episode of BSI was considered.

\section{Definitions}

Bacteremia was considered nosocomial when diagnosed $\geq$ 48-hrs upon initial hospitalization. Onset of bacteremia was defined as day $0\left(\mathrm{~d}_{0}\right)$, which corresponds to the day the first positive blood culture was sampled. In case of coagulase-negative Staphylococci, two positive blood cultures yielding coagulase-negative Staphylococcus on separate occasions within a 48-hrs period, and confirmation of clinical significance of bacteremia by the attending intensivist were required for diagnosis of bacteremia [10]. Blood cultures were routinely performed when the patients' temperature was $\geq 38.5^{\circ} \mathrm{C}$ or when infection was suspected on clinical grounds. Antimicrobial resistance and susceptibility was determined according to the guidelines as recommended by the National Committee for Clinical Laboratory Standards. Antibiotic therapy was defined as 'adequate' when the drug administered had invitro and clinical activity against the isolated strain and when initiated within 48-hours after sampling the positive blood culture. Therapy was considered 'inadequate' when there was no activity both, in-vitro and clinical against the isolated strains or when no drug was administered. Time to adequate antibiotics is defined as the time delay between a blood culture that became positive and the time adequate antibiotics were administered. In our ICU a restricted antibiotic strategy is conscientious followed [11]. The empiric antibiotic regimen administered is based on the underlying pathology, patients' history, local ecology, length of hospitalization, colonization status, presumed inciting focus, and hemodynamic status of the patient. Last-line antibiotics such as carbapenems and glycopeptides are only given to those patients colonized with multi-drug-resistant pathogens or those with a fulminated septic shock. Through mutual deliberation, different specialists (i.e. intensivist, infectious disease specialist, and microbiologist) daily verify whether narrowing the antibiotic spectrum is possible. Further, prophylactic antibiotics are only given preoperatively. For those already receiving antibiotic therapy, onset of BSI should be interpreted as a new outbreak of infection which on its turn will provoke an inflammatory response expressed by CRP and/or WCC changes in the blood. The source of bacteremia was determined by the attending intensivists and microbiologists, based on the presumed portal of entry of the isolated microorganism and by the clinical course. Blood sampling for chemistry is routinely collected each morning at $6 \mathrm{am}$. When multiple determinations were performed during a day, the highest level of CRP and/or WCC was taken into account.

Severity of illness was assessed by means of the Acute Physiology and Chronic Health Evaluation (APACHE) II score and determined daily as a surrogate marker of organ dysfunction aiming to evaluate a patients' clinical evolution. Haemodynamic instability was defined as depend- 
ence of vasoactive or inotropic therapy, acute renal failure as the need for haemodialysis, and respiratory failure as ventilation dependency during ICU stay [12-14].

\section{Statistical analysis}

Variables are described as mean \pm standard deviation (SD) and median (interquartile range). The Mann-Whitney $U$ test and the Chi-square test were used as appropriate. A multivariable logistic regression was performed, including all variables having a $P$-value $<0.10$ in univariate analysis or with plausible relationship with both biomarkers to assess the impact of these determinants on the dynamics of CRP and WCC levels, respectively. Goodness-of-fit was tested by means of the Hosmer-Lemeshow statistic technique. Significance was accepted for a two-tailed $P$-value
$<0.05$. For analysis, SPSS 12.0 (SPSS Inc., Chicago, IL, USA) software package was used.

The present study was approved by the Ethics Committee of the Ghent University Hospital (registration number: B67020072006).

\section{Results}

During the study period we recorded a total of 198 episodes of nosocomial BSI. Ninety-three episodes were excluded because of missing laboratory variables $(n=29)$, when polymicrobial $(n=40)$, or when fungal $(n=20)$ or anaerobic pathogens involved $(n=4)$. For 105 episodes (occurring in 84 patients) all data were available. Of these episodes, 42 were classified as Gram positive bacteremia

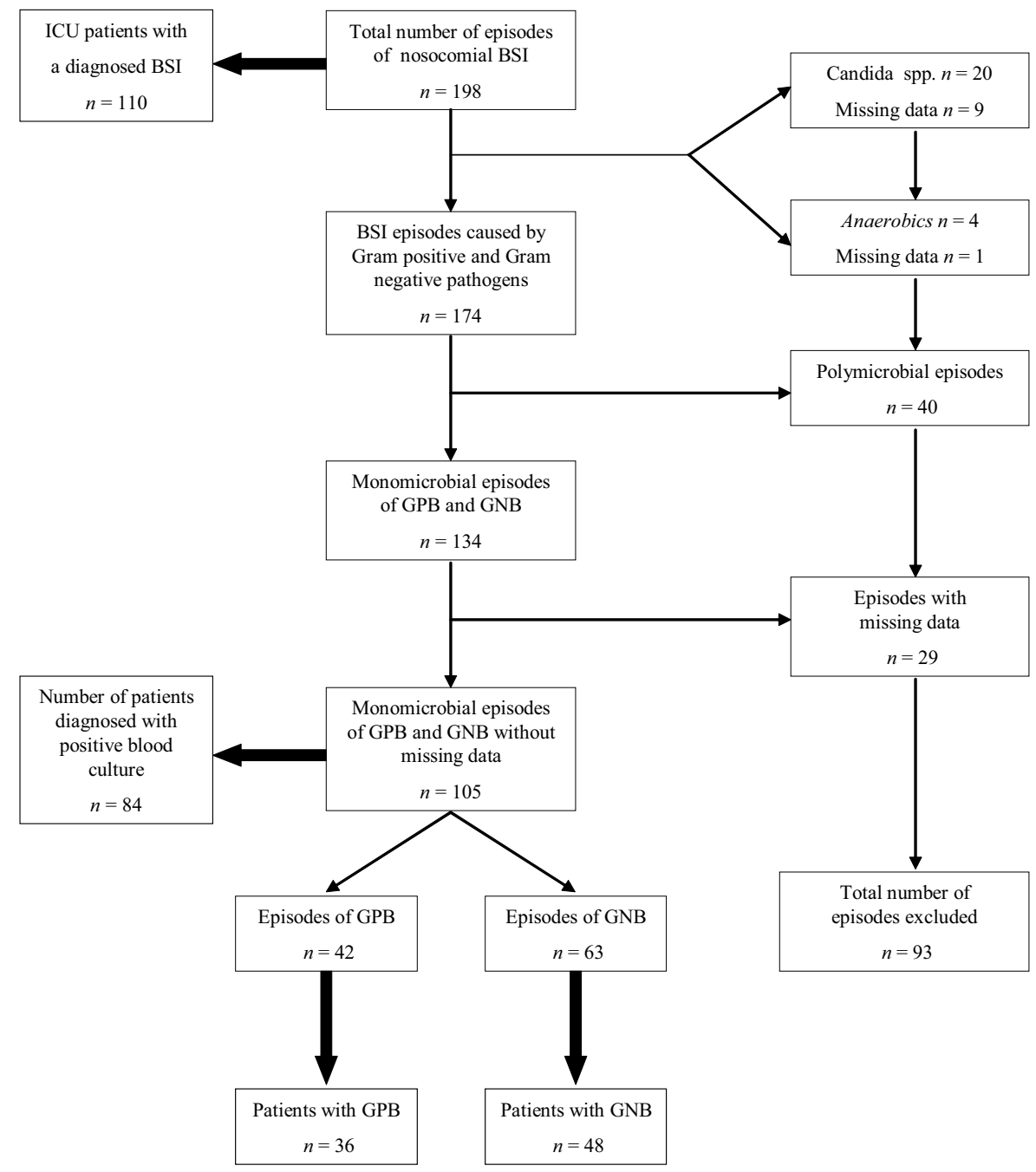

Figure I

Flow chart of exclusion criteria of episodes of nosocomial bacteremia (2003-2004). ICU, intensive care unit; BSI, bloodstream infection; GPB, Gram positive bacteremia; GNB, Gram negative bacteremia. 
Table I: Patient baseline characteristics. SD, standard deviation; APACHE, Acute Physiology and Chronic Health Evaluation; ICU, intensive care unit; LOS, length of stay

\begin{tabular}{|c|c|c|c|}
\hline Characteristic & $\begin{array}{l}\text { Episodes of Gram-positive } \\
\text { bacteremia }(n=42)\end{array}$ & $\begin{array}{l}\text { Episodes of Gram-negative } \\
\text { bacteremia }(n=63)\end{array}$ & $P$ \\
\hline Age, years, mean (SD) & $55.6 \pm 19.5$ & $58.3 \pm 15.2$ & 0.905 \\
\hline Female, No (\%) & $15(4 \mid .7)$ & $16(33.3)$ & 0.497 \\
\hline APACHE II, mean (SD) & $19.1 \pm 6.7$ & $20.5 \pm 7.8$ & 0.400 \\
\hline \multicolumn{4}{|l|}{ Comorbidity } \\
\hline Liver disease, No (\%) & $\mathrm{I}(2.8)$ & $0(0.0)$ & 0.429 \\
\hline \multicolumn{4}{|l|}{ Antibiotic therapy } \\
\hline Adequate therapy $\leq 24-\mathrm{hrs}$, No (\%) & $22(52.4)$ & $48(76.6)$ & 0.010 \\
\hline Adequate therapy $\leq 48$-hrs, No (\%) & $30(70.7)$ & $56(89.6)$ & 0.037 \\
\hline Adequate therapy, No (\%) & $38(90.5)$ & $57(90.5)$ & 0.999 \\
\hline Delay in the start of adequate therapy, mean (SD) & $1.6 \pm 1.6$ & $0.6 \pm 0.8$ & $<0.001$ \\
\hline \multicolumn{4}{|l|}{ Outcome } \\
\hline ICU LOS, median (range) & $16.5(5.5-31.0)$ & $19.5(3.0-30.3)$ & 0.726 \\
\hline ICU LOS before onset of bacteremia, median (range) & $9.0(1.3-24.0)$ & $8.0(2.3-17.8)$ & 0.544 \\
\hline In-hospital mortality, No (\%) & $13(36.1)$ & $22(45.8)$ & 0.503 \\
\hline
\end{tabular}

(GPB) (43\%) (occurring in 36 patients) and 63 as Gram negative bacteremia (GNB) (57\%) (occurring in 48 patients) (Figure 1). Bacterial strains resistant to first line antibiotics were more prevalent encountered in GPB $(P<$ $0.001)$.

Patients with GPB and patients with GNB had comparable age and sex distribution, organ failure during ICU stay, and severity of illness on ICU admission (Table 1). Overall, $90.5 \%$ vs. $90.5 \%$ of episodes were treated adequately $(P=0.999)$, however, there was a significant delay to initiation of adequate therapy in patients with Gram positive aetiology of bacteremia; $52.4 \%$ in patients with GPB compared to $76.6 \%$ in patients with GNB within 24-hrs after

Table 2: Microbiological causes of nosocomial Gram positive and Gram negative bacteremia

\begin{tabular}{lcc}
\hline Organism & $\mathbf{n}$ & $\begin{array}{c}\text { Number of anti- } \\
\text { biotic suscepti- } \\
\text { ble bacteria } \mathbf{n}(\%)\end{array}$ \\
\hline Gram-positive bacteria & 42 & $9(21.4)$ \\
$\quad$ Staphylococcus spp. & 34 & \\
$\quad$ Staphylococcus aureus & $1 \mathrm{I}$ & $1(2.4)$ \\
$\quad$ Coagulase-negative staphylococci & 23 & $0(0.0)$ \\
Streptococci/Enterococci & 8 & $8(19.0)$ \\
Gram-negative bacteria & 63 & $53(84.1)$ \\
Enterobacter spp. & 20 & $13(20.6)$ \\
Pseudomonas aeruginosa & 16 & $15(23.8)$ \\
Klebsiella spp. & 8 & $8(12.7)$ \\
Escherichia coli & 6 & $6(9.5)$ \\
Proteus spp. & 5 & $5(7.9)$ \\
Serratia marcescens & 3 & $3(4.8)$ \\
Acitenobacter & 2 & $2(3.2)$ \\
Stenotrophomonas maltophilia & $\mathrm{I}$ & $0(0.0)$ \\
Morganella morganii & 1 & $1(1.6)$ \\
Flavo bacterium & $\mathrm{I}$ & $0(0.0)$ \\
\hline
\end{tabular}

onset of bacteremia $(P=0.010)$, and $70.7 \%$ compared to $89.6 \%$ within 48 -hrs $(P=0.037)$. Similarly, mean time delay to adequate therapy was $1.6 \pm 1.6$ days vs. $0.6 \pm 0.8$ days $(P<0.001)$ in GPB and GNB, respectively. Microbiological causes of BSI episodes are listed in Table 2.

Serum CRP concentrations were higher in patients with GNB than with GPB from $\mathrm{d}_{0}$ on. Moreover, in GNB patients these levels showed a steady and significant increase from $\mathrm{d}_{-2}$ onward with a peak concentration at $\mathrm{d}_{1}$ $(P=0.009)$, whereas in patients with GPB, these levels showed only a smooth increase (Figure 2). Evaluation of serial WCC levels showed comparable results (Figure 3). Analysis of the time course, as expressed by $\Delta \mathrm{CRP}_{\mathrm{d}-2 \text { to } \mathrm{d}+1}$ and $\Delta \mathrm{WCC}_{\mathrm{d}-2 \text { to } \mathrm{d}_{+1}}$ levels, showed that median $\Delta \mathrm{CRP}_{\mathrm{d}-2 \text { to }}$ $\mathrm{d}+1$ levels for GPB and GNB were $3.1 \mathrm{mg} / \mathrm{dL}(-2.4 \mathrm{mg} / \mathrm{dL}$ $7.8 \mathrm{mg} / \mathrm{dL})$ vs. $6.2 \mathrm{mg} / \mathrm{dL}(0.9 \mathrm{mg} / \mathrm{dL}-14.2 \mathrm{mg} / \mathrm{dL})(P=$ $0.025)$, and median $\Delta \mathrm{WCC}_{\mathrm{d}-2 \text { to } \mathrm{d}+1}$ levels were $180 \times 10^{3}$ cells $/ \mathrm{mm}^{3}\left(-2,100 \times 10^{3}\right.$ cells $/ \mathrm{mm}^{3}-3,500 \times 10^{3}$ cells/ $\left.\mathrm{mm}^{3}\right)$ vs. $1,900 \times 10^{3}$ cells $/ \mathrm{mm}^{3}\left(-1,500 \times 10^{3}\right.$ cells $/ \mathrm{mm}^{3}$ $7,100 \times 10^{3}$ cells $\left./ \mathrm{mm}^{3}\right)(P=0.171)$. We also verified whether an increase of CRP levels from $d_{-2}$ to $d_{+1}$ of $5 \mathrm{mg} /$ $\mathrm{dL}$, and whether an increase of WCC levels from $\mathrm{d}_{-2}$ to $\mathrm{d}_{+1}$ of $5,000 \times 10^{3}$ cells $/ \mathrm{mm}^{3}$ could differentiate between GPB and GNB. Both cutt-offs were exceeded in $9 / 36$ (25.0\%) and $8 / 36(22.2 \%)$ of patients with GPB, compared to $35 /$ $48(72.9 \%)$ and $36 / 48(75.0 \%)$ in patients with GNB $(P=$ 0.011 and $P=0.035$, respectively).

Multivariate logistic regression analysis identified GNB (OR, 5.06; 95\% CI,1.52-16.91; $P=0.008$ ) to be independently associated with a CRP level increase of $5 \mathrm{mg} / \mathrm{dL}$ from $\mathrm{d}_{-2}$ to $\mathrm{d}_{+1}$, whereas APACHE II score was not (OR,0.87; 95\% CI,0.79-0.96; $P=0.006$ ) (Goodness-of-fit; chisquare, $2.46 ; \mathrm{df}, 8 ; P=0.963)$. Gram negative aetiology of bacteremia (OR,3.31; 95\% CI,0.96-11.41; $P=0.040)$ and 


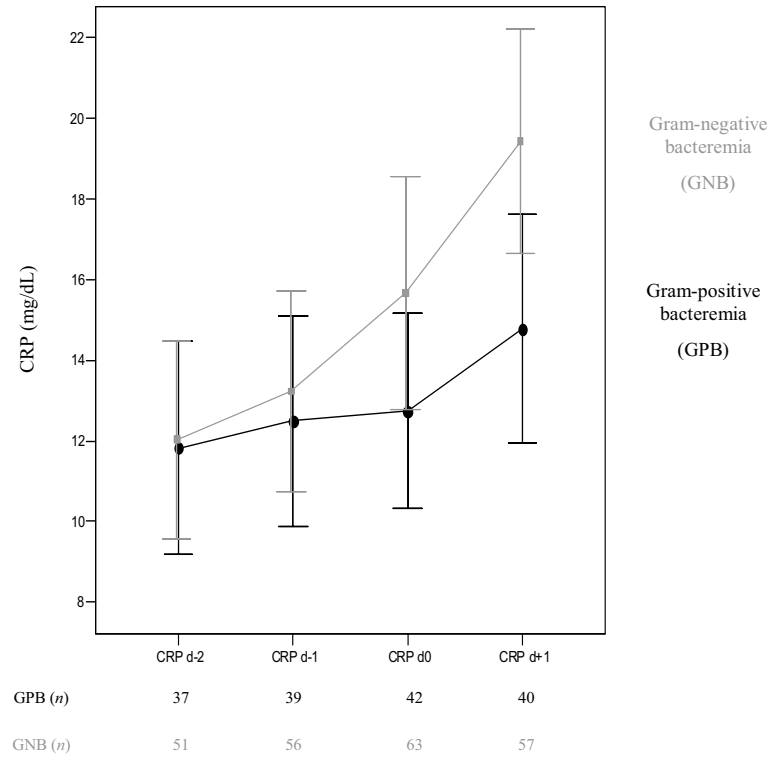

Figure 2

Dynamics of C-reactive protein serum concentrations in ICU patients with nosocomial bacteremia involving either Gram positive vs. Gram negative bacteria.

APACHE II score (OR, 1.10; 95\% CI,1.00-1.20; $P=0.044$ ) (Goodness-of-fit; chi-square,6.45; df,8; $P=0.587$ ) were both independently associated with an increase of WCC levels from $\mathrm{d}_{-2}$ to $\mathrm{d}_{+1}$ of $5,000 \times 10^{3}$ cells $/ \mathrm{mm}^{3}$. Focuses of infection as well as appropriateness of antibiotics were not shown to be independent determinants in the dynamics of both biomarkers (all $P>0.05$ ).

\section{Discussion}

Early initiation of adequate antimicrobial therapy is critical to ensure good outcome in severe infection [15-19]. Therefore, early recognition and accurate diagnosis of bacteremia is highly desirable, and appropriate antibiotics should not be delayed until blood cultures identify the offending pathogen [20]. However, increasing antimicrobial resistance and concerns about antibiotic exposure driving selection of multidrug-resistant strains have complicated both empiric antibiotic choices and clinical decisions whether to start antibiotics. The present study investigated whether Gram positive vs. Gram negative pathogens have different patterns in CRP and WCC count levels in order to help physicians in their daily clinical judgment.

Previous studies comparing groups of patients who received antibiotics because of documented vs. suspected infection, already evaluated serum concentrations of CRP and/or WCC counts in the diagnosis of infection [6,2123]. However, most of these studies used the American College of Chest Physicians/Society of Critical Care Medicine Consensus Conference guidelines to define the presence or absence of sepsis $[3,24]$. Because these criteria are consensually considered to have high sensitivity and low specificity, we therefore selected a very homogeneous group of patients with unequivocal bacterial sepsis.

Although our cohort already had high baseline CRP and WCC count serum concentrations, some differential observation could be made after the onset of bacteremia with respect to both biomarkers. Patients with GPB demonstrated lower CRP and WCC levels at onset of bacteremia, which remained almost stable during the four study days. On the other hand, CRP and WCC levels at $\mathrm{d}_{+1}$, as well as the absolute increase between $\mathrm{d}_{-2}$ and $\mathrm{d}_{+1}$ were significantly higher in patients with GNB. In both groups (patients with GPB vs. GNB) peak concentrations of CRP and WCC levels were observed one day following onset of bacteremia $(P=0.009$, and $P=0.008)$, respectively. In accordance to earlier reports, by combining CRP and WCC measurements we could not further improve specif-

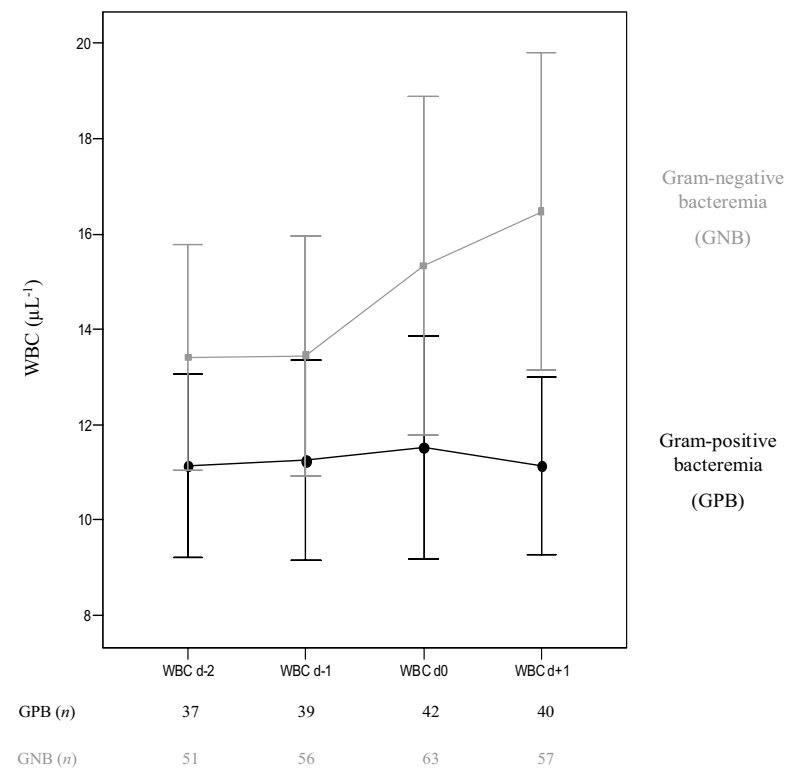

Figure 3

Dynamics of white blood cell count serum concentrations in ICU patients with nosocomial bacteremia involving either Gram positive vs. Gram negative bacteria. 
icity for the diagnosis of bacteremia $[6,25]$. Using $\triangle$ CRP and $\triangle$ WCC levels in order to evaluate their respective evolution over time, multivariate analysis showed that Gram negative aetiology of bacteremia was independently associated with (i) an increase of CRP levels of $5 \mathrm{mg} / \mathrm{dL}$, and (ii) an increase of WCC of 5,000 $\times 10^{3}$ cells $/ \mathrm{mm}^{3}$ from two days prior until one day after onset of bacteremia, respectively. Remarkably, APACHE II score was, however, not independently associated with the first scenario (CRP increase), whereas it was independently associated with the latter (WCC increase). In both models, appropriateness of antibiotic therapy as well as focus of infection had no association with neither CRP nor with WCC.

Attributable mortality rates up to $45 \%$ have been reported in case of an inadequate choice of empirical therapy in patients with nosocomial bacteremia [26]. Because microbiological results generally only are available 48-hrs after blood cultures were obtained, and adjustment of inadequate therapy at this time poorly influences outcome, there is need for clinical or biochemical parameters to warn the clinician of an inadequate empiric choice at an earlier stage in the course $[15,27]$. In our study cohort, episodes of nosocomial BSI due to Gram positive bacteria received similar rates of adequate antibiotics compared with episodes of GNB; however, a substantial delay in the start was observed $(P<0.001)$. We noted a high rate $(47.6 \%)$ of inadequate therapy within the first 24-hrs following onset of infection among episodes of GPB. This figure illustrates that particularly in this subgroup; considerable benefit could be achieved with respect to this time delay. Taken the relationship between the delay in starting adequate antimicrobial therapy and clinical outcome, a role for serial measurements of WCC and especially CRP serum concentrations in the early detection, as well as for follow up of bacteremia among critically ill patients may be presumed. Because in patients with GPB the highest rates of inadequate treatment are recorded, an increase of both CRP and WCC levels could be expected. However, this was not confirmed in our data. No significant differences were found in CRP and WCC levels according to the appropriateness of empirical antibiotic treatment. Although an adequate empirical antibiotic regimen is initiated, an increase of CRP and/or WCC levels is frequently observed over the next 24-hrs or even 48-hrs. Additionally, other events such as recent surgery, inflammatory insult, pancreatitis and trauma may cause fluctuations in CRP levels, respectively. Further, in the GPB-group, coagulase-negative Staphylococci were the most frequently isolated pathogens. In addition to the above, this may also explain the high observed rate of inadequate choice of empirical antibiotics. Though, since these pathogens are considered to be less virulent compared to other Gram positive strains such as Staphylococcus spp., serial measure- ments of CRP and WCC seem to be less relevant for this purpose.

The present study only investigated the dynamics of two variables (CRP and WCC) in their ability to differentiate between bacteremia caused by Gram positive vs. Gram negative pathogens. The short period of observation (4 days, respectively) includes another limitation of this study. Taken into account a longer period could have resulted in additional information (e.g. the amplitude of CRP and/or WCC levels could have been observed to be more pronounced before onset of bacteremia), though in an ICU setting, many other factors associated with increased CRP and/or WCC levels, however, not of infectious origin, are frequently observed. We used the APACHE II score as a surrogate marker of organ dysfunction; however, other scores aimed to assess severity of illness could have resulted in other conclusions. Also, we could not provide data with regard to previous antibiotic therapy in this cohort which might have biased our results. Because our findings are based on a single centre study, one should be careful when interpreting or extrapolating these data. Next, other physical or laboratory criteria such as fever, hypothermia, tachycardia, tachypnea, inflammatory mediators (e.g. interleukine-6, tumor necrosis factor- $\alpha$ ) were not evaluated and might be more straightforward in this assessment. Lastly, as this study was conducted retrospectively, it is recommended to repeat this study with a prospective design. Nonetheless, this study is the first to elaborate on the dynamics of CRP and WCC levels in adult ICU patients with GPB and GNB.

\section{Conclusion}

In conclusion, surveillance of bacteremia in the ICU is crucial in detecting major changes in aetiology such as the increasing incidence of GPB. Our findings suggest that obvious different patterns are observed in patients with nosocomial GPB vs. GNB, with respect to both biomarkers studied. However, their use is less relevant in guiding antibiotic therapy.

\section{Competing interests}

The author(s) declare that they have no competing interests.

\section{Authors' contributions}

DMV collected and analyzed the data, developed the study design and was principal writer of the manuscript. EAH participated in developing our main research questions and contributed in statistical analyses. POD and SIB were involved in critical analysis and writing the manuscript. SIB also collaborated with extracting necessary data. RAP and JDC critically reviewed the manuscript and were involved because of their extraordinary expertise in 
the field. All authors read and approved the final version of the manuscript.

\section{Acknowledgements}

Dominique Vandijck is financially supported by a Doctoral Grant from the Special Scientific Research Fund of the Ghent University. Thanks to G. Verschraegen, MD, PhD from the department of Microbiology and Mr. J. Deschuijmer, MSc from the Hospital Hygiene Team of the Ghent University Hospital for prospectively collecting data concerning nosocomial infections.

Presented in part at the $36^{\text {th }}$ Annual Congress of the Society of Critical Care Medicine, Orlando, Florida, 2007.

Reference: Vandijck DM, Hoste EA, Blot SI, Depuydt PO, Peleman RA, Vogelaers DP, Decruyenaere JM. Dynamics of CRP and WBC Count in Critically III Patients with Nosocomial Gram-Positive versus Gram-Negative Bacteremia. Crit Care Med 2007, 34 Suppl I: P458:A127.

\section{References}

I. Vincent JL: Microbial resistance: lessons from the EPIC study. European Prevalence of Infection. Intensive Care Med 2000, 26 Suppl I:S3-8.

2. Calandra T, Cohen J: The international sepsis forum consensus conference on definitions of infection in the intensive care unit. Crit Care Med 2005, 33(7): 1538-1548.

3. Levy MM, Fink MP, Marshall JC, Abraham E, Angus D, Cook D, Cohen J. Opal SM, Vincent JL, Ramsay G: 200I SCCM/ESICM/ACCPI ATS/SIS International Sepsis Definitions Conference. Crit Care Med 2003, 3 I (4): I 250-I 256

4. Vincent JL, Sakr Y, Sprung CL, Ranieri VM, Reinhart K, Gerlach H, Moreno R, Carlet J, Le Gall JR, Payen D: Sepsis in European intensive care units: results of the SOAP study. Crit Care Med 2006, 34(2):344-353.

5. Vandijck D, Decruyenaere JM, Blot SI: The value of sepsis definitions in daily ICU-practice. Acta Clin Belg 2006, 6 I (5):220-226.

6. Povoa P, Coelho L, Almeida E, Fernandes A, Mealha R, Moreira P, Sabino $\mathrm{H}$ : C-reactive protein as a marker of infection in critically ill patients. Clin Microbiol Infect 2005, II(2): 10I-108.

7. Sprung CL, Sakr Y, Vincent JL, Le Gall JR, Reinhart K, Ranieri VM, Gerlach H, Fielden J, Groba CB, Payen D: An evaluation of systemic inflammatory response syndrome signs in the Sepsis Occurrence in Acutely ill Patients (SOAP) study. Intensive $\begin{array}{lll}\text { Care } & \text { Med 2006, 32(3):42I-427. }\end{array}$

8. Spapen HD, Hachimi-Idrissi S, Corne L, Huyghens LP: Diagnostic markers of sepsis in the emergency department. Acta Clin Belg 2006, $61(3): 138-142$.

9. Kollef M: Appropriate empirical antibacterial therapy for nosocomial infections: getting it right the first time. Drugs 2003, 63(20):2157-2168.

10. Martin MA, Pfaller MA, Wenzel RP: Coagulase-negative staphylococcal bacteremia. Mortality and hospital stay. Ann Intern Med 1989, I I0(1):9-16.

II. Hoste EA, Vandijck DM, Van Holder RC, De Waele J], Lameire NH, Claus S, De Schuijmer J, Dhondt AW, Decruyenaere JM, Verschraegen G, Blot Sl: Health Implications of Antimicrobial-Resistance in Bloodstream Infection Patients with Acute Kidney Injury. Infect Control Hosp Epidemiol 2007, 28(9): I I07-I I IO.

12. Blot S, Vandewoude K, De Bacquer D, Colardyn F: Nosocomial bacteremia caused by antibiotic-resistant gram-negative bacteria in critically ill patients: clinical outcome and length of hospitalization. Clin Infect Dis 2002, 34(I 2): | 600-1606.

13. Hoste EA, Blot SI, Lameire NH, Vanholder RC, De Bacquer D, Colardyn FA: Effect of nosocomial bloodstream infection on the outcome of critically ill patients with acute renal failure treated with renal replacement therapy. J Am Soc Nephrol 2004, I 5(2):454-462.

14. Myny D, Depuydt P, Colardyn F, Blot S: Ventilator-associated pneumonia in a tertiary care ICU: analysis of risk factors for acquisition and mortality. Acta Clin Belg 2005, 60(3): | |4- I2I .
15. Iregui M, Ward S, Sherman G, Fraser V], Kollef MH: Clinical importance of delays in the initiation of appropriate antibiotic treatment for ventilator-associated pneumonia. Chest 2002, I 22(I):262-268.

16. Kollef MH, Sherman G, Ward S, Fraser VJ: Inadequate antimicrobial treatment of infections: a risk factor for hospital mortality among critically ill patients. Chest 1999, I I 5(2):462-474.

17. Kollef MH, Ward S, Sherman G, Prentice D, Schaiff R, Huey W, Fraser $V$ J: Inadequate treatment of nosocomial infections is associated with certain empiric antibiotic choices. Crit Care Med 2000, 28(1 0):3456-3464.

18. Leibovici L, Shraga I, Drucker M, Konigsberger H, Samra Z, Pitlik SD: The benefit of appropriate empirical antibiotic treatment in patients with bloodstream infection. J Intern Med 1998, 244(5):379-386.

19. Colardyn F: Appropriate and timely empirical antimicrobial treatment of icu infections--a role for carbapenems. Acta Clin Belg 2005, 60(2):51-62

20. Blot $S$, Vandewoude K: Early detection of systemic infections. Acta Clin Belg 2004, 59(1):20-23.

21. Luzzani A, Polati E, Dorizzi R, Rungatscher A, Pavan R, Merlini A: Comparison of procalcitonin and C-reactive protein as markers of sepsis. Crit Care Med 2003, 3I(6): I737-I74I.

22. Reny JL, Vuagnat A, Ract C, Benoit MO, Safar M, Fagon JY: Diagnosis and follow-up of infections in intensive care patients: value of C-reactive protein compared with other clinical and biological variables. Crit Care Med 2002, 30(3):529-535.

23. McCabe RE, Remington JS: C-reactive protein in patients with bacteremia. J Clin Microbiol 1984, 20(3):3 I7-3I9.

24. Bone RC, Balk RA, Cerra FB, Dellinger RP, Fein AM, Knaus WA, Schein RM, Sibbald W]: Definitions for sepsis and organ failure and guidelines for the use of innovative therapies in sepsis. The ACCP/SCCM Consensus Conference Committee. American College of Chest Physicians/Society of Critical Care Medicine. Chest 1992, I0 I(6): 1644-I655.

25. Povoa P, Coelho L, Almeida E, Fernandes A, Mealha R, Moreira P, Sabino $\mathrm{H}$ : Pilot study evaluating $\mathrm{C}$-reactive protein levels in the assessment of response to treatment of severe bloodstream infection. Clin Infect Dis 2005, 40( I 2): | 855-I857.

26. Byl B, Deviere J, Saint-Hubert F, Zech F, Gulbis B, Thys JP: Evaluation of tumor necrosis factor-alpha, interleukin-6 and $C$ reactive protein plasma levels as predictors of bacteremia in patients presenting signs of sepsis without shock. Clin Microbiol Infect 1997, 3(3):306-316.

27. Kollef $\mathrm{MH}$ : Inadequate antimicrobial treatment: an important determinant of outcome for hospitalized patients. Clin Infect Dis 2000, 3I Suppl 4:SI3I-8.

\section{Pre-publication history}

The pre-publication history for this paper can be accessed here:

http://www.biomedcentral.com/1471-2334/7/106/pre pub

Publish with BioMed Central and every scientist can read your work free of charge

"BioMed Central will be the most significant development for disseminating the results of biomedical research in our lifetime. "

Sir Paul Nurse, Cancer Research UK

Your research papers will be:

- available free of charge to the entire biomedical community

- peer reviewed and published immediately upon acceptance

- cited in PubMed and archived on PubMed Central

- yours - you keep the copyright 